\title{
Comment on 'comparison of overall survival and perioperative outcomes of laparoscopic pancreaticoduodenectomy and open pancreaticoduodenectomy for pancreatic ductal adenocarcinoma: a systematic review and meta-analysis'
}

\author{
Rui Sun ${ }^{1,2^{*}}$, Yifan Zhang ${ }^{1}$ and Zhe Su ${ }^{1}$
}

\begin{abstract}
Background: To discuss some inaccurate parts of a published systematic review and meta-analysis which was about comparison of laparoscopic pancreaticoduodenectomy and open pancreaticoduodenectomy for pancreatic ductal adenocarcinoma in overall survival and perioperative outcomes.

Methods: Not applicable.

Results: The study enrolled overlapping patient cohorts and patients with a variety of disease histologies, not specific for pancreatic ductal adenocarcinoma. They also reported different conclusion for Ro resection of 2 approaches in result and discussion part. Some data should be revised through statistical method, which could be polled to analysis.

Conclusion: The conclusion of this published systematic review and meta-analysis was not objective; therefor, the study may mislead readers, especially for those who just read the abstract of this study or not analysis this article in detail.
\end{abstract}

\section{Main text}

A recently study by Jiang et al. [1] compared overall survival and perioperative outcomes of laparoscopic pancreaticoduodenectomy (LPD) and open pancreaticoduodenectomy (OPD) for pancreatic ductal adenocarcinoma: a systematic review and meta-analysis,

\footnotetext{
This comment refers to the article available at https://doi.org/10.1186/ s12885-019-6001-x.

* Correspondence: srfighting1201@163.com

'Department of Pediatric Surgery, Capital Institute of Pediatric, No. 2 Yabao Road, Beijing 100020, China

${ }^{2}$ Chinese Academy of Medical Sciences and Peking Union Medical College, Beijing, China
}

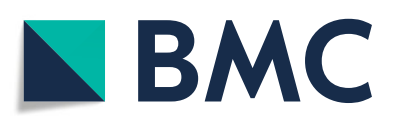

() The Author(s). 2020 Open Access This article is licensed under a Creative Commons Attribution 4.0 International License, which permits use, sharing, adaptation, distribution and reproduction in any medium or format, as long as you give appropriate credit to the original author(s) and the source, provide a link to the Creative Commons licence, and indicate if changes were made. The images or other third party material in this article are included in the article's Creative Commons licence, unless indicated otherwise in a credit line to the material. If material is not included in the article's Creative Commons licence and your intended use is not permitted by statutory regulation or exceeds the permitted use, you will need to obtain permission directly from the copyright holder. To view a copy of this licence, visit http://creativecommons.org/licenses/by/4.0/. The Creative Commons Public Domain Dedication waiver (http://creativecommons.org/publicdomain/zero/1.0/) applies to the data made available in this article, unless otherwise stated in a credit line to the data. that they evaluate clinical efficacy of LPD and OPD for the treatment of Pancreatic ductal adenocarcinoma (PDAC). However, we believe their study has not provided an objective conclusion regarding the oncologic and perioperative outcomes of LPD and OPD in setting of PDAC for the following reasons.

First, 8 studies were included in their meta-analysis, whereas studies of Sharpe et al. [2] and Kantor et al. [3] had overlapping patient cohorts. Their data was both provided by National Cancer Data Base. Sharpe et al. identified all patients 18 years and older diagnosed with 
PDAC who underwent an LPD or OPD between January 2010 and December 2011, while Kantor et al. analyzed data from 2010 to 2013. Therefore, those describing the smaller-scale studies should be excluded in the metaanalysis.

Second, the objective of their study was to confirm efficacy of LPD in patients with PDAC. However, the studies of Speicher et al. [4] and Chen et al. [5] involved patients with a variety of disease histologies, not specific for PDAC. Speicher et al. enrolled 140 patients in total (25 in LPD, 84 in OPD), only including 104 cancer cases without clearly histopathological types reported. Chen et al. involved identified 102 patients having undergone pancreaticoduodenectomy with a pathologically confirmed diagnosis of periampullary tumors, bile duct carcinoma, intra-ductal papillary mucinous neoplasms and pancreatic head cancer between January 2013 and May 2017. We believe these two studies should not be included in the meta-analysis to provide the conclusion.

Third, they demonstrated that LPD resulted in a higher rate of R0 resection compared with OPD. The resulted was showed in Fig. 3 in their study (OR: 1.16, 95\% CI $0.85-1.57, p=0.36$ ). Since the $P$ value was greater than 0.05 the result indicated there was no significant difference between two approaches in R0 resection. Therefore, we believe the conclusion of LPD in R0 resection was incorrect.

In addition, according to the methods of Wan et al. [6], medians with ranges could be converted into means with standard deviations, which should be calculated to pooled the results in the analysis, including R0 resection, estimated blood loss and hospital stay. We suggested the outcomes may be different if they pooled all available data.

Reading of the abstract or failure to analyze the paper in detail may provide the reader with the impression that LPD is equivalent to OPD with respect to overall survival and results in better perioperative clinical outcomes for patients with PDAC whereas we believe this is not the case. The paper does not demonstrate convincingly that LPD introduces equivalent or even improved outcomes compared to OPD, especially for PDAC.

\section{Abbreviations}

LPD: Laparoscopic pancreaticoduodenectomy;"; OPD: Open pancreaticoduodenectomy;; PDAC: Pancreatic ductal adenocarcinoma; OR: Odds ratio

\section{Acknowledgements}

None.

\section{Authors' contributions}

RS contributed to the conception and design, acquisition, analysis, and interpretation, drafted manuscript, critically revised manuscript. RS, YFZ, and ZS critically reviewed the manuscript. All authors revised and approved the final manuscript.
Funding

Fundamental Research Funds for the Central Universities (No. 3332019166).

The funding was used for searching data.

Availability of data and materials

Not applicable.

Ethics approval and consent to participate

Not applicable.

Consent for publication

Not applicable.

\section{Competing interests}

The authors declare that they have no competing interests.

Received: 21 November 2019 Accepted: 6 April 2020

Published online: 16 April 2020

References

1. Jiang YL, Zhang RC, Zhou YC. Comparison of overall survival and perioperative outcomes of laparoscopic pancreaticoduodenectomy and open pancreaticoduodenectomy for pancreatic ductal adenocarcinoma: a systematic review and meta-analysis. BMC Cancer. 2019;19(1):781.

2. Sharpe SM, Talamonti MS, Wang CE, Prinz RA, Roggin KK, Bentrem DJ, Winchester DJ, Marsh RD, Stocker SJ, Baker MS. Early National Experience with laparoscopic Pancreaticoduodenectomy for ductal adenocarcinoma: a comparison of laparoscopic Pancreaticoduodenectomy and open Pancreaticoduodenectomy from the National Cancer Data Base. J Am Coll Surg. 2015;221(1):175-84.

3. Kantor O, Talamonti MS, Sharpe S, Lutfi W, Winchester DJ, Roggin KK, Bentrem DJ, Prinz RA, Baker MS. Laparoscopic pancreaticoduodenectomy for adenocarcinoma provides short-term oncologic outcomes and longterm overall survival rates similar to those for open pancreaticoduodenectomy. Am J Surg. 2017:213(3):512-5.

4. Speicher PJ, Nussbaum DP, White RR, Zani S, Mosca PJ, Blazer DG 3rd, Clary BM, Pappas TN, Tyler DS, Perez A. Defining the learning curve for teambased laparoscopic pancreaticoduodenectomy. Ann Surg Oncol. 2014; 21(12):4014-9.

5. Chen XM, Sun DL, Zhang Y. Laparoscopic versus open pancreaticoduodenectomy combined with uncinated process approach: a comparative study evaluating perioperative outcomes (retrospective cohort study). Int J Surg. 2018;51:170-3.

6. Wan X, Wang W, Liu J, Tong T. Estimating the sample mean and standard deviation from the sample size, median, range and/or interquartile range. BMC Med Res Methodol. 2014;14:135.

\section{Publisher's Note}

Springer Nature remains neutral with regard to jurisdictional claims in published maps and institutional affiliations.

Ready to submit your research? Choose BMC and benefit from:

- fast, convenient online submission

- thorough peer review by experienced researchers in your field

- rapid publication on acceptance

- support for research data, including large and complex data types

- gold Open Access which fosters wider collaboration and increased citations

- maximum visibility for your research: over $100 \mathrm{M}$ website views per year

At $\mathrm{BMC}$, research is always in progress.

Learn more biomedcentral.com/submission 